\title{
DERECHOS LINGÜÍSTICOS Y POLÍTICAS PÚBLICAS
}

\author{
Estudio de PRESEnTACIÓN
}

Pável Humberto Valer Bellota ${ }^{(1)}$

Universidad Nacional de San Antonio Abad del Cusco, Perú

La Organización de las Naciones Unidas ha declarado el 2019, y los años 2022-2032, como año y decenio internacional de las lenguas indígenas. Un acto trascendental de la comunidad internacional que busca llamar la atención acerca de la grave y lamentable pérdida de la diversidad cultural y lingüística. ${ }^{(2)}$

El llamado de la comunidad internacional asume especial importancia en las condiciones actuales de la diversidad lingüística de los Estados postcoloniales. La colonización de América inauguró el proceso de la desaparición de las lenguas del mundo, un proceso largo que ha desembocado en un escenario desastroso. En este sentido, Janse (2003, p. IX) ha mostrado que más de la mitad de ellas han desaparecido en los últimos 500 años, y, coincidentemente con la aceleración de la acumulación del capital y la globalización hegemónica, se estima que más de la mitad de los 6.809 idiomas que se hablan actualmente se encuentran en peligro de desaparecer en el siglo XXI. Hay razones para el pesimismo, sólo 600 de todas las lenguas que se hablan en el mundo tienen posibilidad de sobrevivir a largo plazo. Este autor concluye que estamos en un proceso global, a un ritmo alarmante, de muerte de las lenguas.

Desde una apreciación histórica, Crystal (2000), explica que las lenguas siempre han aparecido, prosperado y muerto, pero la "extinción masiva" de lenguas que amenaza al mundo hoy es un hecho grave y excepcional. ¿Qué hacer al respecto? ¿Es una actitud plausible no hacer nada, no decir nada?

(1) Profesor titular de la Facultad de Derecho y Ciencias Políticas de la Universidad Nacional de San Antonio Abad del Cusco. Doctor por la Universidad del País Vasco (Dpto. de Dcho. Constitucional, Administrativo y Filosofía del Derecho). D.E.A. en Filosofía del Derecho por la Universidad de Zaragoza. D.E.A en Derecho Público por la Universidad Pablo de Olavide de Sevilla. Director de la Revista de la Facultad de Derecho y Ciencias Políticas de la UNSAAC. Email: pavel.valer@unsaac.edu.pe

(2) Sensible respecto a la situación de las lenguas originarias del Perú y de América, con el dossier "Derechos Lingüísticos y Políticas Públicas", nuestra Revista se suma a este llamado. 
Desde la Academia es ineludible actuar para, al menos, poner en evidencia esta situación injusta que causa sufrimiento a muchos pueblos del mundo. Es imprescindible estudiar y diseñar formas sociopolíticas y legales que nos dirijan hacia un escenario de justicia lingüística, es necesario proponer la actuación del Estado en forma de reconocimiento de derechos lingüísticos y la implementación de políticas públicas racionales para revertir las fuentes sociales que pone en peligro los derechos de los hablantes de las lenguas minorizadas.

\section{La justicia lingüística y sus enemigos}

Como ya lo sustentó Dworkin (1984), las instituciones públicas deben reconocer y distribuir derechos para todos. Es incompatible con la democracia que el Estado distribuya bienes u oportunidades de manera desigual, considerando que algunos ciudadanos tienen derecho a más por que merecen mayor consideración. El Estado no debe restringir la libertad sobre la base de que la vida buena de algunos es más noble o superior que la de otros. Por lo tanto, no es justo que el Estado priorice la lengua de un grupo de ciudadanos en desmedro de las de otros, sino, por el contrario, es deber del Estado, y de toda la sociedad, dar garantías, propiciar las condiciones de prosperidad de todas las lenguas, realizar en la práctica la justicia lingüística.

Algunas explicaciones de la justicia lingüística (Van Parijs, 2003) la representan como una forma de justicia cooperativa (intercomunal) entre grupos sociales, así como un aspecto de la justicia distributiva interpersonal. Una práctica que afecta de manera significativa las oportunidades en la vida de los ciudadanos, incluyendo la posibilidad personal de adquirir poder. La justicia lingüística implica además la combinación del esfuerzo personal y las circunstancias sociales que puede favorecer o dificultar el aprendizaje y el uso de una o más lenguas, de tal manera que la desigualdad lingüística puede ser la fuente de una gran injusticia interpersonal.

Estas buenas orientaciones acerca de la justicia lingüística chocan con poderosas causas económicas y políticas que provocan la crisis y la muerte de las lenguas. Entre los factores socioeconómicos, explica Janse, M. (2003, p. X), están la falta de oportunidades de acceso a los recursos de la sociedad "moderna" de los hablantes de lenguas minorizadas, las transformaciones económicas rápidas, la industrialización, la trasformación de las relaciones de trabajo y las formas de producción que quiebran las formas tradicionales de subsistencia de los pueblos originarios. Como factores sociopolíticos que causan la muerte de las lenguas se pueden contar las políticas lingüísticas (oficiales y no oficiales), la discriminación ejercida contra las naciones originarias, la estigmatización de los hablantes, la represión del uso de los idiomas autóctonos, las guerras, etc. 
Las políticas lingüísticas, es decir la actuación del Estado respecto a las lenguas, la priorización por parte del campo económico y del modelo político de un idioma sobre otros, son un factor decisivo en la muerte de las lenguas, y pueden ser, a su vez, una herramienta fundamental de la justicia lingüística. En nuestra realidad social las políticas lingüísticas se desenvuelven en un contexto marcado por el colonialismo occidental que ha demostrado ser extremadamente eficaz en imponer una cultura, una lengua, un solo concepto de vida buena sobre la diversidad. En nuestra América es evidente la subsistencia del modelo lingüístico colonial, o de manera más precisa un imperialismo cultural-lingüístico, orientado a extinguir el uso de los idiomas originarios mediante la castellanización o la imposición de la lengua de los grupos con poder.

Junto a las herencias coloniales en el diseño del Estado, Leung (2018, p. 56) identifica dos obstáculos difíciles de sortear para la justicia lingüística: la construcción de los Estados-nación y, recientemente, el proceso de globalización. El nacionalismo estatal desarrolla políticas de establecimiento de una "lengua nacional" oficial que es una variedad estandarizada y apta para uso estatal, la lengua nacional es el idioma de la vida pública y la educación, y ser competente en esa lengua se convierte en un requisito para la participación, el acceso a recursos y para el ascenso social. Los hablantes de las "otras lenguas" no reconocidas o desdeñadas por el Estado-nación son sometidos a presión para hablar la "lengua nacional", que generalmente se asocia a la idea de modernidad y progreso. Las lenguas de los grupos sociales considerados "minorías" son percibidos como una afrenta, incluso una amenaza, a la unidad de la nación, y los jóvenes ven en poco o ningún valor en aprenderlas.

A lo anterior hay que añadir (Leung 2018), que actualmente se hablan, y subsisten, cerca de 7,000 lenguas y existen solo 193 Estados soberanos. Con estos números es claro que la realidad social del mundo es de multilingüismo, la población de la mayoría de Estados habla varias lenguas, sin embargo, la mayoría de Estados patrocina como oficial una sola de ellas. El nacionalismo estatal, que promueve una sola lengua con valor oficial, es un gran enemigo de la ecología lingüística.

Respecto a la globalización, en especial en cuestiones de integración y participación en la economía global, la comunidad económica y los Estados, impulsan el aprendizaje y la adopción de lenguas globales como el inglés, el castellano, el francés u otras linguas francas, que son consideradas claves para alcanzar oportunidades de desarrollo social y económico. Los medios de comunicación digital, la estandarización del lenguaje y la creencia de que el monolingüismo facilita la eficiencia en la gestión y el crecimiento económico, promueven la reducción contemporánea de la diversidad lingüística (Leung, Op.Cit). 


\section{La expansión del castellano como política lingüística colonial, subsistente hoy}

"Siempre la lengua fue compañera del imperio" decía Elio Antonio de Nebrija en su obra de lingüística española impresa en 1492 (18 de agosto), en plena aventura colombina. Históricamente, uno de los primeros intereses de los peninsulares en tierras americanas ha sido la implantación del castellano como lengua franca. La suplantación lingüística ha sido más trabajosa para los grupos colonizadores que el desalojo del poder que sufrieron los vencidos de las empresas coloniales. En efecto, los hispanos castellanos ocuparon en pocos años el espacio político y social andino, pero su lengua lo está logrando solo al cabo de cinco siglos de dominación cultural y aun con algunas reservas debidas a la resistencia de los pueblos indígenas.

Sanchez Albornoz (2001) detalla que las lenguas indígenas de América formaron parte del debate para implantar la política de consolidación colonial. De hecho, las posiciones más duras mostraban un menosprecio explícito por ellas y un deseo expreso de extinguirlas. El Oidor de Guatemala, Tomás López Medel, escribió en 1550 refiriéndose a la necesidad de expandir el castellano: " $Y$ de esta manera se dará entrada para nuestra lengua y para las cosas de nuestra religión y para desterrar la bárbara lengua de estos [indios], y sus abominables costumbres". En el Perú, el Oidor Juan de Matienzo propuso que se forzara a los indios a aprender el español. Por otro lado se encontraban las posiciones más objetivas y realistas, por ejemplo el Padre Acosta en 1588 escribe: "hay quienes sostienen que hay que obligar a los indios con leyes severas a que aprendan nuestro idioma [...] si unos pocos españoles en tierra extraña no pueden olvidar su lengua y aprender la ajena [...] ¿en qué cerebro cabe que gentes innumerables olviden su lengua en su tierra y usen solo la extraña que no la oyen sino raras veces y muy a disgusto?" (De Acosta, 1952).

Se puede concluir, entonces, que el proceso de castellanización es una campaña permanente desde hace cinco siglos, en desmedro de los idiomas indígenas, que ha tomado forma de política de Estado y que se viene aplicando en la actualidad, bajo la anuencia de la Constitución realmente existente.

La política pública de castellanización comenzó sus andaduras como un instrumento necesario para la propagación del cristianismo, la evangelización fue el norte cultural de la invasión y la lengua solamente un instrumento de prédica. Algunas cédulas incorporadas a la Recopilación consideran en sus preámbulos a las lenguas nativas como incapaces de expresar las complejidades teológicas. ${ }^{(3)}$

\footnotetext{
(3) "...) que en la mejor y más perfecta lengua de los indios no se pueden explicar bien y con propiedad los misterios de la fe, sino con grandes absurdos e imperfecciones". Otros previenen de que los padres transmiten de palabra a los hijos la religión ancestral "se ha tratado y deseado que desde niños aprendiesen la lengua castellana, porque en la suya se dice que les enseñan sus mayores los errores de sus idolatrías, hechicerías y supersticiones, que estorban mucho a su cristiandad". [De Acosta, 1952]
} 
Paralelamente a la religión, la tarea de alfabetizar y enseñar el castellano a los millones de nativos del continente constituyó un trabajo interminable. Cualquier disposición real estaba condenada de antemano a ser insuficiente.

En lugar de operar sobre un conjunto inabarcable, la Corona apostó por actuar desde arriba de la escala social indígena. Se crearon colegios para los hijos de caciques donde se enseñaba el castellano. Ejemplos 'exitosos' de estos colegios para caciques de la nobleza indígena fueron los de Tlatelolco, Texcoco (en México) y Lima y Cusco (en Perú). La cédula de 1550, recogida en la Recopilación de las leyes de los reinos de las Indias (Libro VI, T. VI, Ley XVIII), dice textualmente: "Que a los indios se les pongan maestros, que enseñen a los que voluntariamente las quisieren aprender, como les sea de menor molestia y sin costa y ha parecido que esto pudieran hacer bien los sacristanes como en las aldeas de estos reinos enseñan a leer y escribir la doctrina cristiana" (Sanchez de Albornoz, 2001).

Las campañas de castellanización se fueron haciendo cada vez más agresivas. En 1638, por ejemplo, el obispo de Cuzco escribió al rey "es triste cosa que los latinos y griegos diesen su lengua a los vencidos y nosotros no a estos indios" (Konetzke, 1953, p. 89). El virrey del Perú, Duque de la Palata, lanzó por su cuenta una ambiciosa campaña educativa en 1685 juntó al censo general de los indios, justificándose en que se hallaba "tan conservada en esos naturales su lengua india, como si estuvieran en el imperio del inca, pues sólo en esa Ciudad de los Reyes y en los valles entendían la castellana, que resultaba en lo político y lo espiritual el mayor impedimento para la crianza de los naturales". Disgustado, por este hecho decidió 'sembrar' los Andes de escuelas rurales en todos los pueblos que tuvieran cura. Palata dispuso excluir de los cargos, de cacique para abajo, a los indios que ignoraran el español o no lo hubieran enseñado a sus hijos. Igualmente Carlos III emitió una cédula en 1770 en la que expresaba el anhelo de que desaparecieran las lenguas indígenas y de implantar en su lugar el castellano. Más adelante, promulgó las complementarias de 1778 y 1782 sobre construcción y dotación de escuelas (Konetzke, Ibid).

Las políticas públicas de castellanización basadas en la expansión de la religión y la alfabetización escolar de los indios tienen, por lo tanto, su origen en un planteamiento colonial, y continúan hasta nuestros días basadas más en el mito de la escuela. Como explica Montoya (1986), ya en el siglo XX, los herederos de los españoles en el poder consideraron que el único modo de 'civilizar' a los 'bárbaros' o'salvajes' (nuevos términos propuestos por el etnocentrismo burgués europeo) sería a través de la escolarización forzosa. Occidente fue creando lentamente el mito civilizatorio de la escuela a través de la oposición oscuridadanalfabetismo-salvajismo frente a la luz-alfabetización-civilización, bajo este esquema "(...) la escuela significa liquidar las culturas indígenas entendidas como salvajes". 
Los procesos de alfabetización llevados a cabo por la escuela, después de la declaración de la independencia, tienen la labor de continuar la campaña de castellanización diseñada en la época colonial peruana orientada a homogeneizar culturalmente al país. Basándose en el principio de igualdad, confundido con homogeneización cultural, los programas alfabetizadores se convirtieron en armas políticas-culturales de los sectores conservadores en poder del Estado, útiles en la lucha para acabar con el 'problema' de la diversidad cultural.

Asimismo, actualmente el sistema educativo peruano dominante tiene valores, categorías conceptuales y modos de pensar provenientes de tradiciones occidentales como la hispánica, la griega antigua, la cristiana católica, utiliza una multiplicidad de lenguas latinas ligadas a la sectorización de la ciencia, con una lógica matemática propia que está estrechamente relacionada a la creación de tecnologías, lo cual explica su postura frente a las culturas nativas. De esta manera opera un proceso de "dislocamiento cultural" (Bermúdez Tapia, 2008).

En esta orientación, se produce la impunidad jurídica de la violación de derechos culturales por parte del Estado. Si se desconocen las variables lingüístico culturales y se pretende la implantación de un modelo único, se desconocen varios derechos fundamentales reconocidos la Constitución peruana, como: el derecho a la igualdad "nadie puede ser discriminado por motivo de (...) idioma", (Art. 2, 1०) "toda persona tiene derecho a (...) su identidad, a su integridad moral, psíquica y física y a su libre desarrollo y bienestar". Se incumple el deber de respetar y proteger la pluralidad étnica, reconocidas en la Constitución Política de 1993. (Art. 2.19%).

Junto a la educación y la religión, la migración, ocurrida masivamente en el Perú desde la mitad del siglo XX, ha transformado por completo al país. Los migrantes de las zonas rurales y sus hijos eluden identificarse como indios, quechuas o aimaras. En vez de definirse como tales, prefieren llamarse 'cholos', asumiendo una identidad étnica mestiza más abierta y fronteriza que la de indio.

Este proceso de transformación cultural ha ido de la mano con la expansión del castellano como lengua materna. De allí que, según el último censo, solo un quinto de la población declara tener al quechua u otro idioma indígena como lengua materna. Aunque el castellano es el idioma predominante en el país, la diversidad lingüística es una característica notable de la enorme variedad social y cultural del Perú, como resultado, sobre todo, de la subsistencia de los idiomas de los pueblos indígenas.

En el mundo rural -como explica Chirinos (1999)- el idioma castellano, es para los indígenas una herramienta necesaria para la movilidad social, para 
comunicarse con el mundo occidental y oficial del Estado (que generalmente es un mundo escrito) y para poder acceder a trabajos, no relacionados con la agricultura, para los cuales es necesario saber castellano. En las ciudades (y pequeñas capitales de distrito), la situación es otra: no sólo la comunicación en el ámbito oficial, sino también la comunicación informal, se produce en castellano hegemónicamente. En esas circunstancias es cuando es posible pensar que la lengua indígena es prescindible y muchos padres prefieren que sus hijos no la hablen. El índice de sustitución de las lenguas indígenas por el castellano en estas situaciones es explicable no por lealtad o ausencia de ella sino por la utilidad de la lengua. En las ciudades, generalmente el hablar quechua manifiesta un origen indígena, con la carga peyorativa que el término conlleva para el grupo dominante en el Perú. Entonces, no se percibe casi ninguna ventaja en el hecho de aprender una lengua indígena, y sí mucha ventaja en el hecho de negarla, la ventaja es evitar la marginación social. "En muchas zonas rurales que fueron sometidas a intensos procesos de castellanización desde la escuela es una señal de atraso saber la lengua indígena" (Chirinos, Op. Cit)

El arcaico modelo político cultural, diseñado en la colonia, persiste hoy en el proceso de expansión e implantación del castellano. Las políticas orientadas a extinguir el uso de los idiomas autóctonos, mediante la enseñanza solo en el idioma de los invasores, es parte central de dicho modelo. Ama hina kanqichis, wiraqochakuna!!

\section{Las lenguas maternas, entre colonialidad y Derecho}

La crisis contemporánea de la variedad lingüística, las condiciones sociales, culturales y políticas que causan la extinción de las lenguas, ha sido contestada desde un importante movimiento social, jurídico y político. La idea central que lo aglutina es que la lengua es el centro del alma y del cuerpo de la nación, es la médula misma del pueblo. La lengua materna es parte objetiva de las sociedades, refleja el modo de ser y representa la imagen que las naciones hacen del universo que les rodea. Este pensamiento está vinculado al derecho de autodeterminación de los pueblos (De Obieta, 1993).

La forma democrática de organizar el poder, que es hoy el constitucionalismo democrático, recomienda la existencia de frenos y contrapesos a su ejercicio, de forma que ningún grupo, ningún detentador del poder, pueda ejercerlo de manera abusiva, desplazando a los demás, desdeñando sus necesidades, sus puntos de vista, su cultura, su lengua. Una sociedad democrática debe dotarse de un Derecho específico y de políticas públicas para realizar la justicia lingüística, tiene que dar garantías jurídicas e institucionales para el ejercicio de los derechos lingüísticos. 
Sin garantías jurídicas que protejan la lengua materna, las sociedades están incompletas y no pueden ser sociedades en las que gobierne la libertad, sino únicamente esquemas políticos totalitarios que instauran relaciones de poder cultural y de dominación lingüística. En estos diseños no democráticos, un solo sector étnico -el que domina la lengua del poder- es privilegiado, y la mayoría de ciudadanos son desdeñados o desconocidos por el Estado. La afirmación del derecho a utilizar la lengua materna en ámbitos privados y públicos es una exigencia ineludible para la construcción de una sociedad democrática en la que se pueda tener un buen vivir.

Entendiendo esto, desde UNESCO se ha instaurado el día de la lengua materna como un reconocimiento simbólico a la lucha por la democracia que los universitarios de Bangladesh, integrantes del Movimiento por la Lengua, desplegaron para exigir que acabara la dominación colonial y se reconociera como lengua oficial el Bangalí, idioma materno de la gran mayoría de personas de ese país. Varios integrantes de este movimiento fueron muertos a causa de la carga represiva que el Estado colonial desplegó contra una manifestación pacífica el 21 de febrero de 1952.

La resistencia contra el colonialismo tiene que ser entendida como una entereza contra la más absurda de las dominaciones a la que puede ser sometido un pueblo. Aunque varios no quieran reconocerlo, en muchas de nuestras formas sociales y representaciones jurídicas persiste aun la Colonia. Una de las más eficaces formas de dominación que los esquemas coloniales impusieron en nuestra América fue el imperialismo cultural y jurídico: hacernos creer y convencernos que nuestro mundo, todo lo nuestro cultural, nuestras lenguas, eran lo errado, y que todo lo que viniera de la metrópoli era lo normal, lo correcto, lo considerado culto. Nuestros idiomas fueron constituidos, mediante este imperialismo, en lenguas anormales, minoritarias, rústicas, en expresiones expulsadas de la legalidad, a las que había que borrar para siempre e imponer en su lugar los idiomas "doctos" de la anciana Europa.

Se trataba, en el esquema colonial, de acabar con la conciencia de grupo, de hacer desaparecer a los pueblos americanos de su propia memoria: que se olvidaran de símismos y de sus propias lenguas. La reprobación de la autoconciencia cultural tawantinsuyana buscaba acabar con el concepto racional y el cariño que permitía participar en el grupo lingüístico originario. Este modelo inmoral de desconocimiento político colonial es replicado, en el periodo republicano, por las formas jurídicas que prohíben prácticamente hablar en el mundo legalmente construido y ser parte de la asociación cultural originaria de manera consciente y libre. La castellanización de nuestras sociedades autóctonas es todavía, en la actualidad, una parte elemental de ese diseño colonial de dominación. 
A pesar de todo esto, las representaciones ideológicas coloniales, que chocan claramente contra la libertad y la racionalidad, han entrado en decadencia. Las luchas de los pueblos vienen ampliando paulatinamente los derechos humanos individuales. Junto a ellos han surgido los derechos colectivos de los que son titulares las sociedades, los grupos humanos como conjuntos culturales. Estos derechos de los pueblos propician y hacen posible el disfrute de los derechos individuales, son en última instancia el presupuesto de la buena vida y la libertad. Una porción de esos nuevos derechos son los derechos lingüísticos.

Desde un punto de vista moral ya no es posible sostener que un grupo cultural tiene más derecho que otro a utilizar su lengua, difundirla y hacerla subsistir. Tampoco es jurídicamente posible sostener que diferentes lenguas que se hablan en un país tienen un valor diferente. Por el contrario, toda lengua es parte del patrimonio común de la humanidad, cada uno de los idiomas del mundo es fruto de miles de años de creación humana, y cada vez que se extingue una lengua nuestro patrimonio cultural común se hace más pequeño. Aniquilar un idioma es más grave que incendiar y convertir a cenizas un valioso museo, es condenar a la inexistencia a una nación entera.

\section{El desarrollo y los límites de la legislación lingüística}

La extinción de los idiomas debido a la dominación cultural, y a causa de la injusticia lingüística, debe ser proscrita por ley. Los derechos lingüísticos deben ser reconocidos jurídicamente de manera formal por las legislaciones nacionales. En este sentido UNESCO aprobó, en junio de 1996, la Declaración Universal de Derechos Lingüísticos que reconoce derechos a las comunidades lingüísticas. Esta Declaración establece que todas las lenguas tienen igual valor por ser la expresión de una identidad colectiva y de una manera distinta de percibir y describir la realidad. Por ello, en un contexto democrático, el Estado debe dotar a todas las comunidades lingüísticas de las condiciones necesarias para su desarrollo. Toda persona tiene derecho, por ejemplo, a relacionarse y a ser atendido en su propia lengua por los servicios públicos o administrativos.

Estas apreciaciones garantistas son consideradas como el marco de los derechos lingüísticos reconocidos en el ámbito internacional en instrumentos como el Convenio 169 de la OIT (1989), la Declaración Universal de los Derechos Lingüísticos (1996), el Convenio Marco para la Protección de las Minorías Nacionales (1994), la Declaración de Naciones Unidas sobre los Derechos de los Pueblos Indígenas (2007) y la Declaración Americana sobre Derechos de los Pueblos Indígenas (2016). Junto a estas normas internacionales se encuentran las legislaciones nacionales y regionales. 
Estos instrumentos internacionales han sido muy importantes al exigir la actuación de los Estados y reconocer derechos a las minorías lingüísticas, sin embargo, como dice Leung (2018), su enunciado deja espacios en la penumbra: expresiones como "cuando sea apropiado", "siempre que sea posible", "según la situación de cada lengua", "en la medida de lo posible", debilitan su contenido, devalúan las obligaciones del Estado, hace que las personas individuales no puedan en la práctica demandar o presentar denuncias. La falta de precisión de los instrumentos internacionales ha hecho posible, sin embargo, que la mayor protección de los derechos lingüísticos se encuentre en las legislaciones nacionales.

Para el caso del Perú, debido a la subsistencia del colonialismo en la cultura jurídica, y tal vez por haber sido promulgada antes de la Declaración Universal de Derechos Lingüísticos, la Constitución de 1993 no contempla a plenitud estos derechos. Por el contrario, impone el castellano como idioma oficial para su uso en todo el Perú, y restringe la utilización, "en las zonas donde predominen", del "Quechua, el Aymara y las demás lenguas aborígenes, según la ley". Esta disposición constitucional tendrá que ser revisada oportunamente para hacerla compatible con el nuevo sentido común sobre el reconocimiento pleno de nuestra pluralidad lingüística.

En julio de 2011 se publicó la ley 29735 que detalla los alcances del artículo 48 de la Constitución, y declara de interés nacional "el uso, preservación, desarrollo, recuperación, fomento y difusión de las lenguas originarias del Perú". Esta norma hace un listado de los derechos lingüísticos individuales; entre otros: el derecho a ser reconocido como miembro de una comunidad lingüística, al uso en público y privado de la lengua, a ser atendido por el Estado en la lengua materna y gozar de servicios de traducción simultánea, a la educación en la lengua originaria y al aprendizaje del castellano.

En cuanto a los derechos lingüísticos colectivos, esta ley 29735 sólo establece algunos medios de actuación del Estado para promocionar los derechos de las comunidades lingüísticas: la elaboración por el Ministerio de Educación del Mapa Etnolingüístico del Perú, como herramienta de planificación; el establecimiento de los criterios cualitativos y cuantitativos para determinar el carácter predominante de una lengua originaria en un ámbito geopolítico determinado; la creación del Registro Nacional de Lenguas Originarias; y la política estatal respecto a las lenguas en erosión y peligro de extinción.

Dicha norma no es la primera que se ocupa de las lenguas originarias del Perú, anteriormente lo hicieron el Decreto Ley 21156 que reconoce el Quechua como lengua oficial de la República (en 1975), y la Ley 28106 de Reconocimiento, 
Preservación, Fomento y Difusión de las Lenguas Aborígenes (en 2003) . Estas normas derogadas casi nunca fueron aplicadas mediante políticas públicas específicas y coherentes. La misma suerte corrió durante un buen tiempo la ley 27818 que ordena la educación bilingüe intercultural, aunque actualmente desde algunos organismos del Estado se viene intentando su implementación.

La ley de lenguas originarias vigente tiene la debilidad de haber sido promulgada bajo una norma constitucional que restringe los derechos lingüísticos e impone el castellano como lengua oficial, pero es también la ley de mayor contenido y detalle que se ha promulgado hasta ahora en Perú. Hace algunos años, el Ministerio de Cultura y el Ministerio de Educación elaboraron el reglamento de la ley 29735, Decreto Supremo N004-2016-MC. Queda también la tarea pendiente a los gobiernos regionales de elaborar las ordenanzas que permitan la mejor aplicación y el desarrollo de los derechos lingüísticos en sus territorios.

Se debe reconocer que estas normas jurídicas surgen de una realidad social que ha heredado muchos de los esquemas de dominación cultural de la Colonia, pero son también herramientas que inicialmente pueden servir para ayudar a emanciparnos de esos esquemas injustos, inmorales y antidemocráticos. Son normas que deben mejorarse y aplicarse de manera urgente: varios estudios indican que durante este siglo podrían extinguirse más del 50\% de las lenguas del mundo, y sin ir muy lejos: en Cusco, la ciudad abuela de América, desde 1990 menos del $50 \%$ de los padres transmitió su lengua originaria -el quechua o runasimi- a sus hijos. ¡Usqhaylla ruwasun!

\section{Las políticas públicas necesarias para la preservación de las lenguas}

El Perú es un país multicultural, con varios grupos étnico/nacionales, cada uno con una lengua particular. El fenómeno del plurilingüismo peruano es propio del carácter moderno/post colonial de su sociedad, su Estado y su Derecho. Esta característica es especialmente sobresaliente en la Región Cusco en la que el 59,8\% de la población tiene al quechua como lengua materna (INEI, 2017). Respecto a la lengua, la sociedad nacional oficial, de los que tienen al castellano como lengua materna, es una minoría numérica.

Sin embargo, en Cusco, la mayoría quechuablante ha sido imaginada históricamente y tratada por el Estado como parte de las minorías nacionales. Esto en medio de la subsistencia del modelo lingüístico colonial orientado a extinguir el uso de los idiomas originarios mediante la castellanización. Ante esto, las políticas públicas para la preservación, promoción y difusión de las lenguas autóctonas son una necesidad urgente, y una tarea democrática aun no llevada a cabo por el Estado peruano. 
Tradicionalmente, las instituciones públicas en Perú han actuado desconociendo la existencia de los derechos lingüísticos. Ha habido una desafección por parte del Estado a legislar sobre el régimen de las lenguas. Desde la fundación de la República, solo desde el gobierno de Velasco Alvarado (1968-75) se adoptaron las primeras políticas de reconocimiento del Quechua como idioma oficial. La Constitución de 1979 redujo su oficialidad a las localidades donde era predominante $y$, posteriormente, las políticas lingüísticas se concentraron en el ámbito educativo desde 1991. La Constitución de 1993 reconoció el derecho a la identidad étnica cultural, pero siguió con el diseño anterior restrictivo del quechua. En este escenario, en 2011 se publicó la ley 29735 que declara de interés nacional "el uso, preservación, desarrollo, recuperación, fomento y difusión de las lenguas originarias del Perú".

Hoy, sin embargo, las políticas lingüísticas -oficiales y garantistasson prácticamente inexistentes o, en el mejor de los casos, son muy débiles, se concentran en algunas pequeñas dependencias centrales de los ministerios de educación y cultura, y están lejos de alcanzar los objetivos de la ley.

En América Latina, desde la Academia, se han levantado varias voces en contra de aquel escenario. Como un ejemplo puede citarse el estudio de Pellicer (1997) que presenta los principios y la trayectoria histórica del reconocimiento de los derechos lingüísticos en México y expone cómo las autoridades estatales implementan políticas lingüísticas de inspiración occidental dirigida a los grupos minoritarios.

Otra muestra de esta oposición intelectual a la injusticia lingüística, y una aproximación reciente acerca de la situación del quechua en el Perú, se halla en el informe de investigación elaborado por Rousseau, Dargent, et al. (2017) acerca de la política del multilingüismo en dos regiones con mayorías quechua hablantes. Este estudio busca entender los factores que influyen en la implementación de la normativa relacionada con el quechua en los gobiernos regionales, municipales y la sociedad civil de Cusco y Huamanga, explicando la adopción e implementación de políticas de promoción de las lenguas indígenas. En otra investigación sobre derechos lingüísticos indígenas, Dargent y Rousseau (2019), analizan el caso del Perú en las regiones de Cusco y Ayacucho respecto a la adopción e implementación de derechos lingüísticos para las lenguas minorizadas. Estos autores describen el desenvolvimiento de políticas lingüísticas por parte del Estado, pese a la inexistencia de partidos políticos de base indígena.

Para el caso de Bolivia, el estudio de Rita Cancino (2015) aporta de forma sustancial en cuanto la situación lingüística y el estatus de las lenguas oficiales, y analiza la cuestión de las fronteras y peso de la oficialidad entre unas lenguas y otras. Da cuenta que en el marco de la descolonización se cuenta con la implementación 
de "Ley General de Derechos y Políticas Lingüísticas", No. 269, por la que el Estado Plurinacional de Bolivia reconoce, protege y regula los derechos lingüísticos individuales/colectivos y recupera los idiomas oficiales en riesgo de extinción.

Carmen Sánchez (2018) investiga acerca de las políticas lingüísticas del Ecuador respecto al kichwa, abordando su historia y la aplicación de la "glotopolitica Inka hasta la actualidad". Analiza las políticas sobre las relaciones entre las lenguas y sus sociedades, la posición sociolingüística, la identidad de la lengua, la dimensión política, el período histórico donde el kichwa asume jerarquía política.

Estas muestras intelectuales de la importancia de los derechos lingüísticos destacan la necesidad de desenvolver políticas públicas coherentes y realizables en la práctica y que estén guiadas por un actual sentido común jurídico, presente en las normas internacionales.

Sin embargo, los derechos reconocidos en instrumentos como la Declaración Universal de los Derechos Lingüísticos (1996) o el Convenio Marco para la Protección de las Minorías Nacionales (1994), no se han adoptado plenamente. Lo mismo puede decirse de la Declaración de Naciones Unidas sobre los Derechos de los Pueblos Indígenas (2007) y la Declaración Americana sobre Derechos de los Pueblos Indígenas (2016). Dichas normas internacionales coinciden en el reconocimiento de los derechos a la cultura, identidad y educación indígena fundada en sus conocimientos ancestrales y la preservación de sus lenguas. Igual apreciación puede hacerse del Convenio 169 de la OIT (1989) que protege el derecho de los pueblos indígenas al control de sus instituciones y a una educación para fortalecer sus identidades, tradiciones y lenguas originarias.

Es urgente, entonces, que el orden legal que da garantías a todas las lenguas y reconoce derechos quienes las hablan cobre vigencia real. Además que, junto a ellos, se diseñen políticas lingüísticas de manera descentralizada, desde los Municipios y las Regiones, para promover el reconocimiento practico de los derechos culturales de los grupos minorizados (que no son pocos en Perú, el último censo -INEl, 2017- informa que 3'799,780 personas tienen al quechua como lengua materna).

Al igual que en casi toda América, la gran tarea política pendiente en el Perú es la construcción y profundización de una sociedad política democrática, en la que se dé cabida pluralmente a todas las corrientes, identidades culturales y pensamientos políticos. Parte importante de esta tarea inconclusa es la superación del proceso homogeneizador cultural del periodo republicano y la plasmación jurídica constitucional de esta superación; el reconocimiento y la garantía legal al más alto nivel de mecanismos de reconocimiento de construcción nacional que 
posibiliten a los pueblos indígenas su participación efectiva en la construcción y dirección del Estado peruano que también les pertenece y del cual deben ser igualmente elemento fundador constituyente.

El Estado debe reconocer y garantizar a todos sus pueblos integrantes los mecanismos necesarios para profundizar la "amigable liquidación del pasado colonial" (Van Cott, 2000). La superación institucional del proceso homogeneizador del periodo republicano peruano, tiene indudablemente que dotarse de una fundamentación teórica desde los estudios jurídicos que posibilite la emancipación social y la superación de la imposición autoritaria del castellano como única lengua del Estado.

\section{Referencias}

BERMÚDEZ TAPIA; Manuel (2008). Pérdida de identidades lingüístico culturales en el Perú. Revista Virtual de Antropología. Disponible en la web, a Enero de 2008, en http://www.antropologia.com.br/arti/colab/a5-mbtapia.pdf

CANCINO, R. (2015). El caso de las lenguas oficiales de Bolivia ¿ Algunas lenguas son más oficiales que otras? Las fronteras entre las lenguas oficiales de Bolivia. Sociedad y Discurso, (27). pp 10-36.

CHIRINOS, Andrés (1999). Las Lenguas indígenas más allá del 2000. Revista Andina. CBC, Págs. 453-479.

CRYSTAL, D. (2014). Language death. Cambridge University Press.

DE ACOSTA, José. (1952). De procuranda indorum salute; Madrid: Colección España Misionera. Págs. 357-358. [Cfr. Sánchez-Albornoz, 2001]

DE OBIETA CHALBAUD, J. (1993). El derecho humano de autodeterminación de los pueblos, Tecnos, Madrid, 1993.

DELGADO VIVANCO, Miguel Angel (Dir.); El Aillu, Revista peruana de antropología, etnología, folklore, lingüística e historia; Año 1, Nros. 1-2, CUSCO, Junio-Diciembre de 1945.

DWORKIN, R. (1984). Los derechos en serio, Barcelona. Ariel.

JANSE, M. (2003). Language death and language maintenance: problems and prospects. In Language Death and Language Maintenance: Theoretical, practical and descriptive approaches (pp. 9-17). John Benjamins. 
KONETZKE, R. (Ed.). (1953). Colección de documentos para la historia de la formación social de Hispanoamérica, $1493-1810$ (Vol. 1). Consejo superior de investigaciones científicas (1964). [Cfr. Sánchez Albornoz, Pág. 58]

LEUNG, Janny HC. (2018) "Language rights" at Rathert, M. Handbook of Communication in the Legal Sphere (Vol. 14). Walter de Gruyter GmbH \& Co KG. pp 54-82

MONTOYA, Rodrigo (1986). La democracia y el problema étnico en el Perú. Revista Mexicana de Sociología. Vol. 48, No. 3. Jul. - Sep. 1986, Págs. 45-50.

PELLICER, D. (1997). Derechos lingüísticos en México: realidad y utopía. Presentado en la reunion de la Latin American Studies Association. Guadalajara, México.

ROUSSEAU, S., \& DARGENT, E. (2019). The construction of Indigenous language rights in Peru: A language regime approach. Journal of Politics in Latin America, 11(2), 161-180.

ROUSSEAU, S., DARGENT, E., NAVARRO, A., \& SOSA, P. (2017). La política del multilingüismo en dos regiones con mayorías quechua hablantes: informe de investigación. Cuadernos de Trabajo, PUCP.

SÁNCHEZ BURNEO, C. H., \& Burneo Villamagua, J. S. (2018). Políticas lingüísticas del Ecuador en relación al idioma Kichwa. Innova Research Journal, Vol. 3, No.5 pp. 45-53.

SÁNCHEZ-ALBORNOZ, N. (2001). De las lenguas amerindias al castellano. Ley o interacción en el periodo colonial. Colonial Latin Américan Review, Vol. 10, No. 1. Págs. 49-67.

VAN COTT, Donna L.; The friendly liquidation of the past: the politics of diversity in Latin America; Univ. of Pittsburg Press, 2000.

VAN PARIJS, P. (2003). Linguistic justice. En: Kymlicka, W., \& Patten, A. (Eds.). (2003). Language rights and political theory. pp 153-168. 